\title{
Workplace Setting of Mental Health Nursing Program Graduates in Rwanda
}

\author{
Marie Claire Gasanganwa ${ }^{1}$, Benoite Umubyeyi ${ }^{1}$, Darius Gishoma ${ }^{1}$ \\ ${ }^{1}$ University of Rwanda, College of Medicine and Health Sciences, Rwanda
}

\section{Background}

The department of Mental Health Nursing (MHN) at the University of Rwanda was founded in 1998.Until that time, Rwanda had faced a huge shortage of mental health professionals; specifically, there were 1 psychiatrist, 3 mental health nurses and very few clinical psychologists (less than 5) in the country. The purpose of creating the Mental Health Nursing program was to foster the mental well-being of Rwandans who survived the tragic events related to the 1994 genocide against the Tutsi.The aim of this study was to evaluate the MHN graduates' work place settings in relationship to mental health needs in Rwanda. This was a descriptive study. The respondents were graduates from 2000-2014 and the collection of data related to their workplace was made using phone calls to all former students. About 326 out of $348(93.67 \%)$ were reached and for the 22 $(6.32 \%)$ we did not manage to get information about them.

\section{Results}

Since its existence, the department has graduated 348 mental health nurses at the A1 level who are integrated in the national existing pyramidal structure of care. The employment rate was $90.79 \%$ and most of them were working in hospitals: $26.43 \%$ in district hospitals and $24.13 \%$ in referral hospitals

\section{Conclusion}

The current professional placements of the mental health nursing workforce in Rwanda ascertain that these placements correlate with the National Mental Health Policy. All structures of the national health system are provided but they are far from reaching the grassroots level and mental health needs of the population, 26, $1 \%$ of which had PTSD. Further placement of MHN must reinforce the community level, including Health Centers.

Key words: mental health nursing, work place, Rwanda 